\title{
Kill before being killed: an experimental approach supports the predator-removal hypothesis as a determinant of intraguild predation in top predators
}

\author{
Rui Lourenço \& Vincenzo Penteriani \& \\ Maria del Mar Delgado \& Michela Marchi-Bartolozzi \& \\ João Eduardo Rabaça
}

\begin{abstract}
Intraguild predation (IGP) has been explained in terms of competitor-removal, food-stress and predatorremoval hypotheses. Only the first two hypotheses have been fairly well studied. To test the predator-removal hypothesis as a force determining IGP in avian predators, we performed a field experiment to simulate the presence of an IG predator (eagle owl Bubo bubo dummy) in the surrounding of the nests of four potential IG prey (black kite Milvus migrans, red kite Milvus milvus, booted eagle Aquila pennata and common buzzard Buteo buteo). To
\end{abstract}

\author{
Communicated by E. Korpimäki \\ R. Lourenço ${ }^{\circ}$ V. Penteriani $*$ M. M. Delgado \\ Department of Conservation Biology, \\ Estación Biológica de Doñana, \\ C.S.I.C., c/Americo Vespucio s/n, \\ 41092 Seville, Spain \\ R. Lourenço $(*)$ : J. E. Rabaça \\ LabOr - Laboratory of Ornithology and Institute of \\ Mediterranean Agricultural and Environmental Sciences, \\ University of Évora, \\ 7002-554 Évora, Portugal \\ e-mail: ruifazendalourenco@gmail.com \\ V. Penteriani \\ Finnish Museum of Natural History, \\ Zoological Museum, University of Helsinki, \\ 00014 Helsinki, Finland \\ M. M. Delgado \\ Metapopulation Research Group, \\ Department of Biosciences, University of Helsinki, \\ 00014 Helsinki, Finland \\ M. Marchi-Bartolozzi \\ Bourne Bridge Cottages, Little Abington, \\ Cambridge CB21 6AN, UK
}

discard the possibility that an aggressive reaction towards the eagle owl was not related to the presence of the IG predator, we also presented a stuffed tawny owl Strix aluco, which is a potential competitor but cannot be considered an IG predator of the studied diurnal raptors considered in the experiment. While almost always ignoring the tawny owl, raptors chiefly showed an interspecific aggressive behaviour towards their IG predator. Our results seem to support the predator-removal hypothesis, as the IG prey may take advantage of the diurnal inactivity of the IG predator to remove it from their territory. However, the recorded behaviour may be also considered as a special variety of mobbing (i.e. a prey's counter-strategy against its predator), where the mobber is sufficiently powerful to escalate predator harassment into deliberate killing attempts. In their turn, eagle owls can respond with an IG predatory behaviour aimed at removing IG prey species which are highly aggressive mobbers.

Keywords Bubo bubo - Interspecific aggression • Interspecific competition · Mobbing · Raptors ·

Superpredation

Introduction

Interspecific interactions among vertebrate top predators are often highly aggressive, ending in the killing and sometimes the eating of one of them (Heithaus 2001; Mikkola 1976; Palomares and Caro 1999; Sergio and Hiraldo 2008). Since these intraguild predation (IGP) events are sometimes symmetrical, a top predator can either be the killer or the victim of another top predator (mutual IGP; Polis et al. 1989). Aggressive interactions among vertebrate apex 
predators, like IGP or superpredation, have been raising increasingly more interest, mainly due to their potential to shape community structure (Crooks and Soulé 1999; Johnson et al. 2007; Schmitz et al. 2000), but also because these are common and widespread behaviours (Caro and Stoner 2003; Palomares and Caro 1999; Sergio and Hiraldo 2008).

The main reasons proposed to explain the evolution of IGP in vertebrate top predators are: (1) active removal of competitors and free up shared prey (competitor-removal hypothesis); (2) obtaining energy in situations of scarce availability of trophic resources (food-stress hypothesis); and (3) direct elimination of a potential killer threatening the top predator or its offspring (predator-removal hypothesis). Some lines of evidence seem to support these hypotheses: the victim is sometimes not consumed (or is only partially eaten); and predatory interactions among top predators are more common when prey is less abundant (competitor-removal hypothesis: Palomares and Caro 1999; Sunde et al. 1999) or after prey populations crash (foodstress hypothesis: Korpimäki and Norrdahl 1989; Lourenço et al. 2011; Serrano 2000; Tella and Mañosa 1993). However, there are still few empirical evidences supporting these three hypotheses, and to our knowledge the predatorremoval hypothesis has never been tested before (only risks of mutual predation have been so far explored; Palomares and Caro 1999). Despite increasing interest for the IGP's ecological and behavioural frameworks, there are still many loose ends in the theoretical reasoning and empirical evidences determining and justifying the emergence of IGP, as researchers have mainly been focused on the study of the consequences of IGP rather than its causes (Linnell and Strand 2000; Palomares and Caro 1999; Sergio and Hiraldo 2008).

By simulating the presence of an IG predator (the eagle owl B. bubo) near the nest site of four of its IG prey (black kites Milvus migrans, red kites Milvus milvus, booted eagles Aquila pennata and common buzzards Buteo buteo), we performed a field experiment to test if the predatorremoval hypothesis, kill before being killed, could represent one of the factors engendering IGP by eagle owls. The eagle owl represents a useful biological model for testing IGP hypotheses because: it is a quite well studied superpredator in the context of IGP (Lourenço et al. 2011; Sergio et al. 2003, 2007); birds of prey show extremely aggressive responses towards eagle owls (Slagsvold 1982; Zuberogoitia et al. 2008); and it was recently shown that both the competitor-removal and food-stress hypotheses do not fully explain IGP in this top predator (Lourenço et al. 2011). Moreover, eagle owls and diurnal raptors may overlap in space, but show asynchrony in temporal rhythms of activity, which represents a favourable scenario to test the predator-removal hypothesis: eagle owls can easily prey on most diurnal raptors, catching them unaware in the darkness (Mikkola 1976), whereas diurnal raptors attack roosting eagle owls or owlets when they detect them in daylight (authors' observations). Although very few cases of predation by diurnal raptors on eagle owls have been published, and only by golden eagle Aquila chrysaetos and white-tailed eagle Haliaaetus albicilla (Mikkola 1976), smaller raptors have the potential to kill eagle owls and their mobbing behaviour might displace them. In this case, the risks taken to attack (mobbing or attempt to kill) their larger predator may be compensated by the advantage of a safer environment in which to reproduce (i.e. diurnal raptors increase their fitness by removing a potential predator). Therefore, IGP could be the result of the following counter-strategies: (a) diurnal raptors attack eagle owls to avoid being preyed themselves or their offspring during night; and consequently (b) eagle owls carry out IGP to avoid diurnal fatal attacks and potentially dangerous mobbing behaviours, since all those diurnal raptors breeding close to their regular roost or nesting site may represent, during the day, a menace to the nocturnal predator. However, we need to draw attention to the possibility that, in the context of our experiment and study species, the predator-removal hypothesis might be considered as a counter-strategy of a species subject to IGP (diurnal raptors), rather than the driving force behind the evolvement of IG-predatory interactions. In a broader perspective, the kill before being killed hypothesis, could therefore be considered as a special variety of mobbing (i.e. a prey's counter-strategy against its predator), where the mobber is sufficiently powerful to escalate predator harassment into deliberate killing attempts.

\section{Methods}

\section{Study area}

The study was performed in Doñana National Park, southwestern Spain $\left(37^{\circ} 0^{\prime} \mathrm{N}, 6^{\circ} 30^{\prime} \mathrm{W}\right)$, a large wetland located in the estuary of the river Guadalquivir. The area is mainly composed of Mediterranean scrublands scattered with cork oaks Quercus suber, stone pines Pinus pinea woods, as well as small Eucalyptus plantations. This region is favourable to test the predator-removal hypothesis because it holds a dense breeding population of raptors (Sergio et al. 2009; Suárez et al. 2000).

\section{Eagle owl diet data}

For a potential IG prey, the risk of trying to kill its IG predator, before it has the opportunity to prey on it, is only justified if a real threat of being preyed exists. A way to 
demonstrate that a potential IG prey is effectively under predation risk is to evaluate its frequency in the IG predator's diet. For this reason, we analysed pellets and prey remains collected between 2005 and 2009 in eight eagle owl territories in the study area. We determined 1277 prey items using bone and feather identification keys and a reference collection (Laboratory of Archaeo-sciences, IGESPAR, Portugal).

\section{Experimental procedure}

A way to corroborate the predator-removal hypothesis is to demonstrate that, if a roosting eagle owl is discovered near an active nest of a diurnal raptor, it will be strongly attacked. If we are able to show that potential IG prey (diurnal raptors) try to kill their most dangerous IG predator (eagle owls), we will achieve a double result supporting the predator-removal hypothesis for both groups. IG prey and predator perform a "killing race" to avoid nocturnal and diurnal fatal attacks, respectively. We simulated a predatorremoval scenario by presenting a stuffed eagle owl dummy in 25 different sites (separated at least $500 \mathrm{~m}$ ) and closer than $500 \mathrm{~m}$ (see below) to occupied nests of at least one of the diurnal raptors (27 black kite, four red kites, 11 booted eagle and three common buzzard nests), during their breeding period (April-June 2009). All trials were carried out when we observed that at least one of the breeders was near its nest. Because the diurnal raptor species involved in the experiment show light sexual dimorphism for both size and coloration, it was impossible to record the sex of individuals. Each trial lasted $30 \mathrm{~min}$, and we categorized individual behaviour into two different response types: (1) passive behaviour-the dummy does not provoke any reaction on the breeder that detected it, or after detecting it, the raptor soared several times above the owl, emitted alarm calls, and/or perched close to it; (2) interspecific aggression-the raptor dived towards the dummy without contact or directly attacked the owl, knocking it down with its talons. In the last case, the trial ended immediately after we observed the attack with contact. To discard the possibility that interspecific aggressive behaviours of diurnal raptors were not related to IG predator presence (e.g. attacks were simply the result of an intruder's presence or a predation act), we performed an equal number of trials with a stuffed tawny owl Strix aluco dummy using the exact same procedure. The tawny owl is not an IG predator of the diurnal raptors involved in the experiment, but instead it can be seen as a competitor or a prey (Mikkola 1976; Sunde et al. 2003). In Doñana National Park, tawny owls feed mainly on insects and small mammals, and frequently use raptors' nests to breed, overlapping in diet and habitat niches with the studied diurnal raptors (R. F. Lourenço, unpublished data). In the experiment we always used the same two owl dummies, which were placed on a cork base, approximately $1 \mathrm{~m}$ above the ground. Both dummies were in typical perched position. Tawny and eagle owl dummies were placed in the exact same visible place, facing the same direction. No playback of the owls' calls was employed since we were simulating the presence of a roosting individual near diurnal raptors' nests. The presentation order of eagle and tawny owl dummies was randomized to avoid a training effect (Penteriani et al. 2007), and visits to the same site were made in consecutive days. During the experiment, we avoided disturbing incubating individuals and remained the minimum time required in each site. We placed the dummies as quickly as possible and then controlled the experiment from a distance and hidden inside a car or bushes. Actually, the experiment did not seem to have any negative effect on the raptors involved, as we did not register any nest or territory abandonments.

\section{Statistical analysis}

In a first approach, we considered for each trial if the owl dummy was attacked by any individual of any of the four diurnal raptor species or ignored by all diurnal raptors that detected the dummy. We then used a $2 \times 2$ contingency table (Zar 1999) to check if the responses obtained in the trials were independent of the owl dummy used. In a second approach, we considered the 45 encounters of a different individual of diurnal raptor with the eagle owl dummy and the 35 encounters with the tawny owl dummy, obtained in the 25 trials with each dummy. We then checked the effects of the nominal variables: owl dummy (eagle owl, tawny owl), diurnal raptor (black kite, red kite common buzzard, booted eagle), time of day (08:00-11:00, 11:00-14:00, 16:00-20:00), and dummy's distance to raptor's nest $(<100$, 100-300, 300-500 m), on observing a passive or an interspecific aggressive response using a generalized linear mixed model (GLMM) fit by the Laplace approximation (Bolker et al. 2008). We used the site where the trial was done as a random factor. Interactions between explanatory variables were tested, although none of them improved the model's AIC. All statistics were performed in $\mathrm{R}$ 2.9.2 statistical software (R Development Core Team 2009) with package lme4 (Bates and Maechler 2009).

\section{Results}

The eagle owl diet analysis in Doñana showed that diurnal raptors represented in average $3.7 \pm 3.8 \%$ of the prey (53 diurnal raptors preyed in all eight territories). The average percentages of the four studied diurnal raptors in the eight territories were: black kite, $1.6 \pm 2.3 \%$ ( $n=27$ individuals); 
red kite, $0.3 \pm 0.7 \%$ ( $\mathrm{n}=3$ individuals); common buzzard, $0.2 \pm 0.3 \%$ ( $n=3$ individuals); booted eagle, $0.1 \pm 0.3 \%(n=2$ individuals).

During the experiment, the eagle owl dummy was attacked in 16 trials (64\%; Fig. 1) and ignored in the other nine trials (36\%), whereas the tawny owl dummy was mostly ignored (22 trials; 88\%) and attacked in only three trials (12\%). The contingency table showed that the responses are significantly different between the owl dummies $\left(x^{2}=12.22, \mathrm{df}=1, \mathrm{p}=\right.$ $0.0005)$. In the 16 cases of interspecific aggression towards the eagle owl dummy, we registered 11 direct attacks where the diurnal raptor stroke with its talons the head of eagle owl, pulling head or neck feathers and throwing it down the mount. We consider that such attacks would have caused significant injuries or, more generally, the death of a living eagle owl, i.e. the behaviour reflected an intention to harm and not just trying to scare a potential predator. In the remaining five times, the diurnal raptor dived with talons opened without touching the dummy, more like a mobbing behaviour. From the three interspecific aggressions towards the tawny owl dummy, only one consisted of an attack hitting the head, while the other two where mobbing behaviours similar to those observed with the eagle owl dummy.

The time taken from detection to attack with contact with the eagle owl dummy varied from 32 to $1,410 \mathrm{~s}$ (average \pm SE $1 / 4667 \pm 436 s ; n=11$ ). The only attack with contact with the tawny owl dummy took $1,147 \mathrm{~s}$ since its detection.

The owl dummy species was the only significant variable in the GLMM, with diurnal raptors showing a higher frequency of aggressive responses in the presence of the eagle owl dummy $(\beta=-2$. 296, $S E=0.72, z=-3.17, P=0.002)$.

\section{Discussion}

We present direct empirical evidence supporting the reduction of predation risk as one of the possible causes

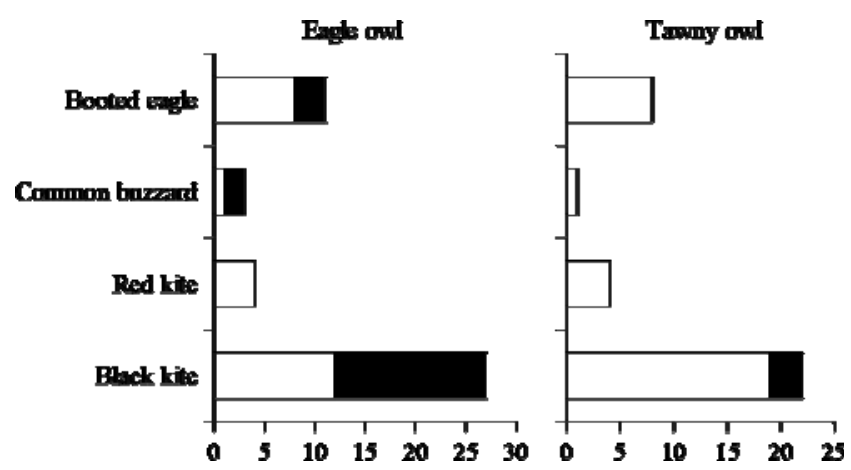

Fig. 1 Number of behavioural responses (white, passive behaviour; black, interspecific aggression) obtained for the four species of diurnal raptors when faced with eagle owl ( $n=45$ interactions; in 25 trials) and tawny owl dummies ( $\mathrm{n}=35$ interactions; in 25 trials) of IGP in vertebrate predators. The diet analysis of eagle owls in Doñana showed that diurnal raptors were frequently consumed, taking into account the known patterns of IGP in eagle owls (Lourenço et al. 2011). Therefore, diurnal raptors should easily perceive eagle owls as their potential predators (Sergio et al. 2003). The results of our field experiment showed a high attack frequency (mobbing) and a considerable risk of serious injury or death for a top predator, the eagle owl, when detected during the day by its potential IG prey (i.e. diurnal raptors). This strong interspecific aggressiveness is also well known by researchers using live eagle owls to trap diurnal raptors (Zuberogoitia et al. 2008). Thus, one encounter should perhaps be enough for an eagle owl to perceive large- and medium-sized diurnal raptors as highly aggressive mobbers and potential predators. Accordingly, we can suggest that: (1) because diurnal raptors may take advantage of the diurnal inactivity of eagle owls to try to remove one of their principal predators, (2) then eagle owls would benefit from removing diurnal raptors because these are potential predators as well, when sharing the same home range. Such a lethal relationship may be exacerbated in high density conditions of the mutual IG predators, like in Doñana National Park, where there may be a lower availability of enemy free space (predators and competitors) and where species share the nest sites (in this area eagle owls often breed in nests of diurnal raptors, Penteriani et al. 2008).

In our opinion, the fact that the tawny owl dummy (representing a competitor but not a predator of diurnal raptors) caused very few aggressive responses, compared to the eagle owl dummy, represents a good evidence of this experiment supporting the predator-removal hypothesis. If the aggressive response of IG diurnal raptors was only triggered by the will to remove a competitor, we should have found a similar frequency of attacks on eagle and tawny owl dummies, or perhaps, more attacks to the tawny owl, since it is, supposedly, an easier species to subdue than eagle owls. Thus, the competitor-removal hypothesis seems to fail in explaining the observed aggressive responses of diurnal raptors towards the eagle owl dummy. The IGP attempt of diurnal raptors on eagle owls seems mostly the result of extreme mobbing or brood defence behaviours.

IGP predation in large vertebrates (carnivores and raptors) is usually asymmetrical and size-based, and it has been mainly seen as an extreme form of interference competition (Palomares and Caro 1999; Ritchie and Johnson 2009; Sergio and Hiraldo 2008; Sunde et al. 1999). In this context, the IG predator is granted two main advantages: the removal of a competitor and an energetic input (Polis et al. 1989). The eagle owl is more powerful than the diurnal raptors we considered in this study and, thus, this interaction is prone to be asymmetrical. This is 
perhaps the most common outcome, as diurnal raptors are frequently preyed by eagle owls, while the opposite is anecdotal (Lourenço et al. 2011; Mikkola 1976). But still, as we found in this study, diurnal raptors are very aggressive towards eagle owls, feeding back this interaction into a possible age-structured mutual IGP scenario, even if predatory events would suggest an asymmetrical phenomenon. Although we do not exclude the additional effects of the competitor-removal and food-stress hypotheses, our results may represent the first evidence supporting the possibility that IGP by eagle owls on diurnal raptors might be triggered by the predator-removal hypothesis (they identify a potential predator, not a competitor). However, we cannot discard the (non-mutually exclusive) possibility that the observed behaviours expressed towards the eagle owl (as well as the tawny owl) dummies may be explained in the frame of mobbing behaviour (i.e. a defence strategy), rather than IGP behaviour per se. In the light of general mobbing (or brood defence) theory (Alcock 1998), a stronger reaction against a real threat than against a species that is more or less harmless is exactly what should be expected.

The behavioural perception of an exploitative competitor is less probable than the obvious identification of an interference competitor as an enemy (Krüger 2002). Moreover, as we observed in this experiment, interference competition interactions between these species might probably result in killing or predation attempts (see also Krüger 2002), being most likely that diurnal raptors identify eagle owls (and vice versa) as IG predators rather than as competitors. Also, considering the possibility that a species could be both seen as competitor and predator, then the release from a potential killer should bring more advantages and more immediate to IG prey's individual fitness than eliminating a competitor (Hakkarainen and Korpimäki 1996; Krüger 2002; Sih et al. 1985). Thus the predator removal could be a stronger behavioural mechanism inducing IGP than competitor removal.

Although our results can be considered as a first direct support to the role played by the removal of a predator in driving IGP, some expectations resulting from the predatorremoval hypothesis still need to be explored to improve our understanding of the links between IGP and the predatorremoval scenario. For example, we found no differences in the proportion of responses among diurnal raptor species and at different distances from nests, as could be initially expected. This might have resulted from an insufficient sample size, but the results can have important consequences in the conservation of the species involved in this complex interaction. Among important points that should be addressed in future studies are: (1) if the degree of IGP is proportional to the abundance of the most aggressive IG prey; (2) if more aggressive IG prey species are more frequently consumed than less aggressive species; and (3) if
IG prey species are preferentially removed of the core areas of home ranges (i.e. near active nests and main roost sites). We suggest that the predator-removal hypothesis should also be tested in other interacting pairs of top predator species and in different conditions of density and resource availability. Another related step forward would be to understand if non-guild mobbers, alike IG mobbers, can also be preferential victims for dominant IG predators, as a way to reduce the costs of being mobbed (Pavey and Smyth 1998; Pettifor 1990; Sunde et al. 2003). Finally, we recommend that future studies investigating the causes of IGP in vertebrates, should bear in mind the possibility of mutual IGP scenarios, and besides the competitive and energetic perspectives, the predator-removal behavioural mechanisms should also be included as potential triggers.

Acknowledgements We thank F. Goytre, C. Lee-Ray and Tiffany for their help in field work, S. Santos for statistical advice and revision, and E. Korpimäki, J. Valkama and an anonymous referee for useful comments that improved the manuscript. The study was funded by a research project from the Consejería de Medio Ambiente, Junta de Andalucía (EXPTE.:700/2005/M/00./). RL was supported by a doctoral degree grant from Fundação para a Ciência e Tecnologia, Portugal (BD/27434/2006), VP by a grant from the Ministry of Education and Science, C.S.I.C. (Proyectos Intramurales Especiales), and a grant from the Spanish Secretaría General de Universidades, Ministry of Education (Salvador de Madariaga Program), and MMD by a postdoctoral grant from the Spanish Ministry of Science and Innovation and a post-doctoral grant from the Academy of Finland.

\section{References}

Alcock J (1998) Animal behavior: an evolutionary approach. Sinauer Associates, Sunderland

Bates D, Maechler M (2009) lme4 — Linear mixed-effects models using S4 classes. Version 0.999375-31. http://me4.r-forge.r-project.org/

Bolker BM, Brooks ME, Clark CJ, Geange SW, Poulsen JR, Stevens MHH, White JSS (2008) Generalized linear mixed models: a practical guide for ecology and evolution. Trends Ecol Evol 24:127-135. doi:10.1016/j.tree.2008.10.008

Caro TM, Stoner CJ (2003) The potential for interspecific competition among African carnivores. Biol Conserv 110:67-75. doi:10.1016/S0006-3207(02)00177-5

Crooks KR, Soulé ME (1999) Mesopredator release and avifaunal extinctions in a fragmented system. Nature 400:563-566. doi:10.1038/23028

Hakkarainen H, Korpimäki E (1996) Competitive and predatory interactions among raptors: an observational and experimental study. Ecology 77:1134-1142. doi:10.2307/2265582

Heithaus MR (2001) Predator-prey and competitive interactions between sharks (order Selachii) and dolphins (suborder Odontoceti): a review. J Zool 253:53-68. doi:10.1017/S0952836901000061

Johnson CN, Isaac JL, Fisher DO (2007) Rarity of a top predator triggers continent-wide collapse of mammal prey: dingoes and marsupials in Australia. Proc R Soc B 274:341-346. doi:10.1098/rspb.2006.3711

Korpimäki E, Norrdahl K (1989) Avian predation on mustelids in Europe 1: occurrence and effects of body size variation and life traits. Oikos 55:205-215 
Krüger O (2002) Interactions between common buzzard Buteo buteo and goshawk Accipiter gentilis: trade-offs revealed by a field experi- ment. Oikos 96:441-452. doi:10.1034/j.1600-0706.2002.960306.x Linnell JDC, Strand O (2000) Interference interactions, co-existence and conservation of mammalian carnivores. Divers Distri 6:169_ 176. doi:10.1046/j.1472-4642.2000.00069.x

Lourenço R, Santos SM, Rabaça JE, Penteriani V (2011) Superpredation patterns in four large European raptors. Pop Ecol 53:175-185. doi:10.1007/s10144-010-0199-4

Mikkola H (1976) Owls killing and killed by other owls and raptors in Europe. Br Birds 69:144-154

Palomares F, Caro TM (1999) Interspecific killing among mammalian carnivores. Am Nat 153:492-508. doi:10.1086/303189

Pavey CR, Smyth AK (1998) Effects of avian mobbing on roost use and diet of powerful owls, Ninox strenua. Anim Behav 55:313318. doi:10.1006/anbe.1997.0633

Penteriani V, Delgado MM, Alonso-Alvarez C, Sergio F (2007) The importance of visual cues for nocturnal species: eagle owls signal by badge brightness. Behav Ecol 18:143-147. doi:10.1093/ beheco/arl060

Penteriani V, Lourenço R, Delgado MM (2008) El fenómeno de la colonización de Doñana por parte del búho real: patrones espacio-temporales de la población y efectos sobre las comunidades de aves y mamíferos. Final Report, C.S.I.C. - Junta de Andalucía, EXPTE.:700/2005/M/00.

Pettifor RA (1990) The effects of avian mobbing on a potential predator, the European kestrel, Falco tinnunculus. Anim Behav 39:821-827. doi:10.1016/S0003-3472(05)80945-5

Polis GA, Myers CA, Holt RD (1989) The ecology and evolution of intraguild predation: potential competitors that eat each other. Ann Rev Ecol Syst 20:297-330. doi:10.1146/annurev. es.20.110189.001501

R Development Core Team (2009) R: A language and environment for statistical computing. R Foundation for Statistical Computing, Vienna, Austria. ISBN 3-900051-07-0, URL: http://www.Rproject.org

Ritchie EG, Johnson CN (2009) Predator interactions, mesopredator release and biodiversity conservation. Ecol Lett 12:982-998. doi:10.1111/j.1461-0248.2009.01347.x

Schmitz OJ, Hambäck PA, Beckerman AP (2000) Trophic cascades in terrestrial systems: a review of the effects of carnivore removals on plants. Am Nat 155:141-153. doi:10.1086/303311
Sergio F, Hiraldo F (2008) Intraguild predation in raptor assemblages: a review. Ibis 150(s1):132-145. doi:10.1111/j.1474919X.2008.00786.x

Sergio F, Marchesi L, Pedrini P (2003) Spatial refugia and the coexistence of a diurnal raptor with its intraguild owl predator. J Anim Ecol 72:232-245. doi:10.1046/j.13652656.2003.00693.x

Sergio F, Marchesi L, Pedrini P, Penteriani V (2007) Coexistence of a generalist owl with its intraguild predator: distance-sensitive or habitat-mediated avoidance? Anim Behav 74:1607-1616. doi:10.1016/j.anbehav.2006.10.022

Sergio F, Blas J, Hiraldo F (2009) Predictors of floater status in a longlived bird: a cross-sectional and longitudinal test of hypotheses. J Anim Ecol 78:109-118. doi:10.1111/j.1365-2656.2008.01484.x

Serrano D (2000) Relationship between raptors and rabbits in the diet of Eagle Owls in southwestern Europe: competition removal or food stress? J Raptor Res 34:305-310

Sih A, Crowley P, McPeek M, Petranka J, Strohmeier K (1985) Predation, competition, and prey communities: a review of field experiments. Ann Rev Ecol Syst 16:269-311. doi:10.1146/ annurev.es.16.110185.001413

Slagsvold T (1982) Mobbing: goshawks attacking stuffed eagle owl. Br Birds 75:330-333

Suárez S, Balbontín J, Ferrer M (2000) Nesting habitat selection by booted eagles Hieraaetus pennatus and implications for management. J Appl Ecol 37:215-223. doi:10.1046/j.13652664.2000.00503.x

Sunde P, Overskaug K, Kvam T (1999) Intraguild predation of lynxes and foxes: evidence of interference competition? Ecography 22:521-523. doi:10.1111/j.1600-0587.1999.tb01281.x

Sunde P, Bølstad MS, Desfor KB (2003) Diurnal exposure as a risk sensitive behaviour in tawny owls Strix aluco? J Avian Biol 34:409-418. doi:10.1111/j.0908-8857.2003.03105.x

Tella JL, Mañosa S (1993) Eagle owl predation on Egyptian vulture and northern goshawk: possible effects of a decrease in European rabbit availability. J Raptor Res 27:111-112

Zar JH (1999) Biostatistical analysis. Prentice Hall, New Jersey

Zuberogoitia I, Martínez JE, Martínez JA, Zabala J, Calvo JF, Azkona A, Pagán I (2008) The dho-gaza and mist net with Eurasian eagle-owl (Bubo bubo) lure: effectiveness in capturing thirtheen species of European raptors. J Raptor Res 42:48-51. doi:10.3356/JRR-05-31.1 